\title{
Beyond Calories: A Holistic Assessment of the Global Food System
}

\author{
Hannah Ritchie*, David S. Reay and Peter Higgins \\ University of Edinburgh, Edinburgh, United Kingdom
}

The global food system is failing to meet nutritional needs, with growing concerns for health related to both under-, over-consumption and severe micronutrient deficiency. The 2nd Sustainable Development Goal (SDG2) targets the end of malnutrition in all forms by 2030. To address this challenge, the focus around food security and malnutrition must be broadened beyond the scope of sufficient energy intake to take full account of total nutrient supply and requirements. Here, for the first time, we have quantitatively

OPEN ACCESS

Edited by:

Pietro Paolo Michele lannetta, James Hutton Institute,

United Kingdom

Reviewed by:

Daniela Moura de Oliveira Beltrame, Biodiversity for Food and Nutrition,

Brazil

Hamid El Bilali,

Istituto Agronomico Mediterraneo di

Bari, Italy

Michael A. Grusak,

Children's Nutrition Research

(USDA-ARS), United States

${ }^{*}$ Correspondence:

Hannah Ritchie

hannah.ritchie@ed.ac.uk

Specialty section:

This article was submitted to

Nutrition and Environmental

Sustainability,

a section of the journal

Frontiers in Sustainable Food Systems

Received: 30 January 2018

Accepted: 20 August 2018

Published: 14 September 2018

Citation:

Ritchie H, Reay DS and Higgins $P$ (2018) Beyond Calories: A Holistic

Assessment of the Global Food

System.

Front. Sustain. Food Syst. 2:57.

doi: 10.3389/fsufs. 2018.00057 mapped the global food system in terms of energy, protein, fat, essential amino acids, and micronutrients from "field-to-fork," normalized to an equitable per capita availability metric. This framework allows for the evaluation of the sufficiency of nutrient supply, identifies the key hotspots within the global food supply chain which could be targeted for improved efficiency, and highlights the trade-offs which may arise in delivering a balanced nutritional system.

Keywords: global food system, nutrition, food availability, food losses, sustainable food

\section{INTRODUCTION}

\section{Global Malnutrition Burden}

The global food system is currently failing to meet the nutritional needs of a growing human population (FAO et al., 2015; FAO, 2017b). The standard measure of poor nutrition-caloric hunger-indicates that 795 million (one-in-nine) people were undernourished in 2014-2016 (FAO, 2017b). The Food and Agriculture Organization (FAO)'s most recent analysis suggests that under business-as-usual (BAU) progress, by 2030, 653 million people will remain undernourished globally (FAO, 2017b). These metrics, however, severely underestimate the scale of the challenge in delivering a nutritionally-sufficient diet for everyone (Sukhdev et al., 2016). Malnutrition exists in various forms beyond insufficient energy intake: it's estimated that approximately one billion people suffer from protein deficiency (Wu et al., 2014); one-third of under-5 s are stunted (low height-for-age; Ahmed et al., 2012); more than two billion suffer from micronutrient deficiencies (also known as "hidden hunger"; von Grebmer et al., 2014); and paradoxically two billion adults are classified as overweight or obese, with strong links to an alarming rise in the prevalence of non-communicable diseases (NCDs), such as type-II diabetes and heart disease (International Food Policy Research Institute, 2016). This challenge exists across countries of all income levels, with a growing number of developing nations experiencing a "triple burden"an increase in the prevalence of obesity in parts of the population alongside the wide prevalence of undernourishment and micronutrient deficiencies (Alexandratos and Bruinsma, 2012). The widespread and multifaceted nature of malnutrition not only comes at a severe social cost, but also an economic one. It's estimated that malnutrition could negatively impact global gross domestic product by $10 \%$ per year (Horton and Steckel, 2011). 
The Millennium Development Goals largely limited measures of malnutrition to energy undernourishment (United Nations, 2001). The Sustainable Development Goals (SDGs) have broadened this perspective to include the ambition to end all forms of malnutrition (SDG2) by 2030 (United Nations, 2015a), making this challenge inclusive of all countries at all income levels. Whilst the importance of nutrition is exemplified in the second SDG (SDG2), malnutrition forms a core component of many of the other SDGs, with highly relevant indicators in gender equality, healthy life, poverty, reducing inequality, education, peace and justice, and growth and employment (International Food Policy Research Institute, 2016). The co-dependence of agriculture and environment means it is also tightly linked to Goals 13-15, concerned with climate change, oceans and terrestrial ecosystems. In particular, global food production must adapt to environmental change, but also play a key role in climate change mitigation (IPCC, 2014).

The inadequacy of a caloric-based outlook to, by itself, address these challenges has led to recent calls for a major reframing of our global approach to malnutrition and food research (Haddad et al., 2016; Sukhdev et al., 2016). A few fundamental components emerge as crucial to this shift: the food system must be reviewed with the inclusion of all essential nutritional elements; holistically, across the full agricultural and food value chain to identify entry points for change; and with relevant metrics which can be more widely understood and communicated.

\section{Research Aims}

Here, for the first time, we have mapped the global flow of all essential nutritional components-including energy, protein, fat, micronutrients (essential vitamins and minerals), and amino acids-from "field-to-fork," assuming per capita equity (i.e., utilizing an average per capita metric) availability. This was quantified drawing upon the FAO's Food Balance Sheets (FBS) for 2011 (the latest complete dataset available; FAO, n.d.), FAO regional commodity waste estimates (FAO, 2011b); and FAO and the United States Department of Agriculture (USDA) nutrient databases (FAO, 2001, 2016; USDA, 2016; see Methods).

This analysis serves several purposes. Firstly, by measuring average nutrient intakes relative to recommended requirements, it reviews the capacity with which the current food system could sufficiently nourish the current global population through equitable distribution. Secondly, it identifies the key system inefficiencies, which can be compared both across stages of the value chain and across nutrients, to better understand the entry points which can be targeted for improved efficiency. These entry points may differ between macro- and micronutrients, making a holistic analysis crucial to recognizing the trade-offs and balance in optimizing both. This will allow for further quantification and analysis of the capacity of the food system to meet growing nutritional demands through time, and SDG targets by 2030 . Whilst this has been evaluated previously in the form of caloric supply (Cassidy et al., 2013; BajŽelj et al., 2014), this discussion must be extended to all essential nutrients if SDG2 is to be met.

There are three core components necessary to deliver an effective food system for everyone:
(1) a sufficient range of food items necessary for a diet of balanced nutritional quality must be produced and available for consumption at the household level;

(2) a sufficient range of commodities must be regionally and locally accessible for consumers;

(3) a diverse range of nutritious products must be affordable for consumers at all income levels.

Our analysis primarily focuses on the first of these three components. By normalizing to an average per capita metric, such an analysis fails to capture the global inequalities in nutrient availability and intake which exist, and that are reflected in the latter two components. However, the framework utilized in this study holds merit in its replicability: it can be easily scaled for use at a range of levels including regional, national or local contexts. In this case, such analyses can prove effective in assessing the capability of national food systems or trade to meet domestic nutritional requirements.

\section{METHODS}

\section{Nutrient Availability Estimates}

The global food system was mapped from crop production through to per capita food consumption using FAO Food Balance Sheets (FBS) from its FAOstats databases (FAO, n.d.). FBS provide quantitative data (by mass) on production of food items and primary commodities, and their utilizations throughout the food supply chain. Such data are available at national, regional and global levels. To maintain consistency and ensure use of the best-available data throughout the analysis, FAO data have been utilized at all possible stages. Food Balance Sheet data for 2011 have been used, these being from the latest full dataset available.

Food Balance Sheets provide mass quantities across the supply chain. In this analysis, we include all stages of the supply chain available within the FBS (with exception of post-harvest losses and wastage, which are further disaggregated as described in section Food Wastage Estimates): crop production, exports, imports, stock variation, re-sown produce, animal feed, other non-food uses, and food delivered to households. Data on all edible food items and commodities across all food groups are included within these balances; a full list of included commodities are detailed in Supplementary Table 1. In calculation of animal feed production in the form of oilcakes, FAO figures were normalized to primary crop equivalents based on cake-to-crop conversion factors applied by Davis and D'Odorico (Davis and D’Odorico, 2015).

In order to estimate the total nutrient value in the eight supply chain stages above, mass quantities of each food commodity (for example, tons of wheat, rice, soyabeans) were multiplied by energy (kcal), fat and protein content of each key food item/commodity (for example, 350 kilocalories per $100 \mathrm{~g}$; FAO, 2001). This therefore gives the total quantity of kilocalories, grams of protein and fat at each stage of the global supply chain.

\section{Food Wastage Estimates}

FBS provide a single value of supply chain losses for each commodity-grouped as a single category "losses." Here we 
have attempted to provide food loss and waste figures by specific stage in the supply chain. Our disaggregated food loss figures have been calculated based on the commodityspecific regional percentages provided in other FAO literature (FAO, 2011b). These percentage figures break food losses down across seven commodity groups and five supply chain stages (agricultural production, post-harvest handling and storage, processing and packaging, distribution and consumption). The applied percentage values by commodity type and supply chain stage are provided in Supplementary Table 2. Food losses at each of the five loss or wastage stages were therefore first estimated by region (using mass quantities and percentage loss figures by region), and summed in order to derive a global figure.

It's important to note that the FAO FBS report final nutrient figures as "food availability"-these figures have not been corrected for consumption wastage, meaning they often overestimate final consumption. In this study we have attempted to correct for consumption-level wastage by applying the "consumption" commodity-specific percentage loss figures (one of the five stages of loss and wastage defined above) and subtracting from "food availability" figures. This provides a more precise indication of food availability-here, we have referred to final food availability as "residual food availability."

\section{Corrections for Protein Quality, Amino Acid and Micronutrient Availability}

Protein quality is a key concern for many developing nations as a result of a predominance of grain-based diets, with grains tending to have poorer digestibility and amino acid (AA) profiles than animal-based products and plant-based legume alternatives(Swaminathan et al., 2012; Wu, 2016). Whilst cerealdominant diets may meet total protein requirements, protein intake is often of poor quality and insufficient to meet actual nutritional requirements (Bouis et al., 2011).

Taking full account of protein quality impacts would require quantification based on the FAO's recommended Protein Digestibility Corrected Amino Acid Score (PDCAAS) and, more recently, the Digestible Indispensable Amino Acid (DIAA) score (WHO/FAO/UNU Expert Consultation, 2007; FAO, 2011a). These scoring systems calculate protein quality based on a food's most limiting AA. Although ideal for the assessment of protein quality in individual food items, and occasionally applied for analysis of simple dietary composition, PDCAAS and DIAA methods present significant challenges when applied to an aggregate of $100+$ food items-limiting AA's, for example, can cancel out between different food items (FAO, 2011a). To best quantify limitations in protein quality, protein intakes have therefore been corrected for digestibility using FAO digestibility values (World Health Organization, 1991), with amino acid profiles analyzed separately. The production and distribution of individual indispensable amino acids (FAO, 2011a) were quantified using FAO and USDA composition databases (FAO, 2016; USDA, 2016).

The sufficiency and requirements of AA intake is measured differently to that of macro- and micronutrients. Whilst the latter are measured in terms of total consumption, AAs are quantified relative to grams of protein intake (mg amino acid per gram of total protein; WHO/FAO/UNU Expert Consultation, 2007). An amino acid is considered to be "limiting" if its relative (mg $\mathrm{g}_{\text {protein }}{ }^{-1}$ ) quantity falls below its AA-specific requirement. When this occurs, protein synthesis cannot proceed beyond the rate at which the limiting AA is available (FAO, 2011a). In other words, overall protein utilization (the total quantity of protein used in the body) is only as effective as its limiting AA. Since amino acid limitation is defined based on AA contents per gram of protein, the relative AA values were calculated using the total protein content at each supply chain stage.

In a similar manner to macronutrients, micronutrients were quantified at each stage of the food chain by multiplying mass quantities of specific commodities by their equivalent micronutrient contents from FAO INFOODS (FAO, 2016) composition and USDA nutrient databases ${ }^{33}$. It's important to note that our study attempts to quantify the average supply and availability of nutrients through the commodity chainmicronutrients can additionally be lost through processes such as cooking (World Health Organization, 2005), impacting on the true level of consumption in individuals. These additional losses are difficult to quantify. As such, we might consider our results to be an upper estimate on micronutrient availability. In this analysis, we have selected eight micronutrients which are typically analyzed in nutritional assessment: calcium, iron, zinc, folate, and vitamins $\mathrm{A}, \mathrm{B}_{6}, \mathrm{~B}_{12}$, and $\mathrm{C}$.

It should be noted that this analysis considers only natural micronutrient sources within the commodity chain. Vitamins and minerals are frequently added to food products at the processing stage (Miller and Welch, 2013). This food fortification process is widely implemented across many developed nations, and can be an essential source of key micronutrients. Such practices are, however, largely absent across most developing nations where natural dietary sources of micronutrients are also likely to be lowest.

\section{Assessment of Nutritional Sufficiency}

For consistency, and to provide a better understanding of the food system down to the individual level, all metrics have been normalized to average per person per day (pppd) metric-this was calculated by dividing total nutrient contents by 2011 global population figures from UN population data (United Nations, 2015b). This therefore provides an average value, assuming equitable distribution across the population.

In order to assess the capacity of the global food system to deliver sufficient nutrients for all, this average pppd nutrient availability was compared relative to energy, macronutrient, amino acids and micronutrient recommended requirements. We acknowledge that nutritional requirements vary significantly between individuals depending on gender, age, size, and levels of activity - this study is unable to capture such heterogeneity. However, it does provide an important comparison of equitable average availability and average recommended requirement.

In this study we have defined caloric requirements by the World Health Organization's (WHO's) minimum threshold of 2,100 kcal pppd (UNHCR/UNICEF/WFP/WHO, 2004) and $50 \mathrm{~g}$ pppd of protein (World Health Organization, 1991). Daily 
requirements for fatty acids are less straightforward to determine, relative to energy or protein-there is no widely-agreed figure for total fat requirements for adequate nutrition (FAO/WHO, 2008). A commonly adopted recommended level of fat intake in national dietary guidelines is $70 \mathrm{~g}$ pppd of total fat (FAO, 2017a), however this should not be interpreted as absolute requirements in the manner of energy or protein. The resolution of food balance sheet data does not allow us to adequately quantify the availability to the level of specific fatty acids. As a result, although we have mapped pathways of total fat availability through the food system in a similar manner to energy and protein, we have not here attempted to quantity the prevalence of potential insufficiency.

Micronutrient Estimated Average Requirement (EAR) values were used to determine recommended dietary requirements. EAR is defined as the median required intake and is based on the assertion that nutrient intake and requirements are independent; the distribution of requirements falls symmetrically around the EAR value; and the distribution of nutrient intakes is much larger than that of requirements (World Health Organization, 2005). Micronutrient requirements-in contrast to some dietary needs such as energy, which have larger inter-individual variabilities in requirement-meet these criteria. Individuals which fall below the EAR value are deemed to be at risk of deficiency. This means that in order to ensure global requirements are met, all intakes must surpass the EAR (not just the average intake). WHO guidelines (World Health Organization, 2005; WHO/FAO/UNU Expert Consultation, 2007) and recommended demographic requirements for calculation of global population EARs (for individuals $>12$ months of age) have been followed using UN age and gender demographic data (United Nations: Department of Social Economic Affairs, 2013). Full data on EARs by age and gender group, and population weightings are provided in Supplementary Tables 3, 4. Individuals which fall below EAR values are defined as being at risk of deficiency.

Amino acid requirements and sufficiency are more complex to assess since they are dependent on total protein intake. Here we have derived a population-weighted average requirement based on AA-specific concentration requirements by age and demographic data. UN age and gender demographic data is provided in Supplementary Table 3. AA requirements by age are provided in Supplementary Table 5, and are taken from WHO recommendations (WHO/FAO/UNU Expert Consultation, 2007). WHO estimates are derived assuming individuals' total protein intake meets requirements for their body mass (i.e., they meet the grams of protein per kilogram of body mass requirement).

\section{RESULTS AND DISCUSSION \\ Energy and Macronutrients}

The three nutrient pathways (energy, protein and fat) from agricultural production through to food eaten are shown in Figures 1A-C.

Caloric pathways in the food system are the most welldocumented to date. Our analysis indicates an average global per capita availability of 2,687 kcal pppd in 2011, well above the minimum requirements of 2,100 kcal pppd. Our figure is slightly lower than the FAO's reported average caloric supply of 2,869 kcal pppd (FAO, n.d.), since we have attempted to estimate residual availability after correction for wastage at the consumption level. This is in contrast to FAO figures, which reports food available for consumption, without correction for wastage at the consumer level (FAO, 2001). This result-that globally we produce more than enough to meet current energy needs if equitably distributed-is already well-established (Foley et al., 2011; Cassidy et al., 2013; BajŽelj et al., 2014). Our analysis provides further support for this conclusion. In reality, an estimated two billion overconsume, and close to 800 million are left undernourished (International Food Policy Research Institute, 2016).

Results of this analysis suggest that, once corrected for digestibility, average protein availability was $63 \mathrm{~g}$ pppd. Despite surpassing the $50 \mathrm{~g}$ pppd minimum requirement, the distribution of intakes around this average value is likely to be larger than that of energy; the unit costs of protein are generally higher than that of carbohydrates or fats, making protein more income-dependent than energy intake (Drewnowski, 2010). This is particularly important for many developing nations where consumption of animal-based products and plant-based alternatives such as pulses are often low (Dror and Allen, 2011; Varadharajan et al., 2013). Protein quality is an important factor to consider in evaluating whether intake is sufficient. Studies often report that average regional or national intakes meet $50 \mathrm{~g}$ pppd requirements (Ranganathan et al., 2016), however, there are examples of low- and middle-income countries - such as Indiawhere dominant protein sources are cereal- or plant-based, where average intake can fall below this requirement once digestibility has been considered (Ritchie et al., 2018).

Our analysis suggests that, with equitable distribution, availability of fat would have been $105 \mathrm{~g}$ pppd in 2011 -well above the $70 \mathrm{~g}$ pppd typically recommended in national dietary guidelines (FAO, 2017a). It is well-established that individual intakes of dietary fat are often in excess of recommended guidelines, particularly in developed nations (FAO, n.d.). This is of concern from a health perspective, with strong links between dietary fat intake, obesity and NCDs such as heart disease and stroke (Bray et al., 2004; Malik et al., 2013). However, it's also important to acknowledge the physiological role of fat in nutritional outcomes, and the negative health impacts which can occur through inadequate consumption. Fat plays an important role in the absorption of key micronutrients (FAO/WHO, 2008); low fat intake, as remains the case in many developing nations (FAO, n.d.), therefore serves to exacerbate cases of micronutrient deficiency which are prevalent in low-income communities (Brown et al., 2004; White et al., 2017). The large variations in global intakes of fat therefore have important health implications at both ends of the spectrum.

Whilst the availability of macronutrients at the household level is of prime importance, the average supply of energy, protein and fat are generally well understood (FAO et al., 2015; FAO, n.d.). Of greater interest for building future food resilience and more sustainable food systems is to understand the complete food 

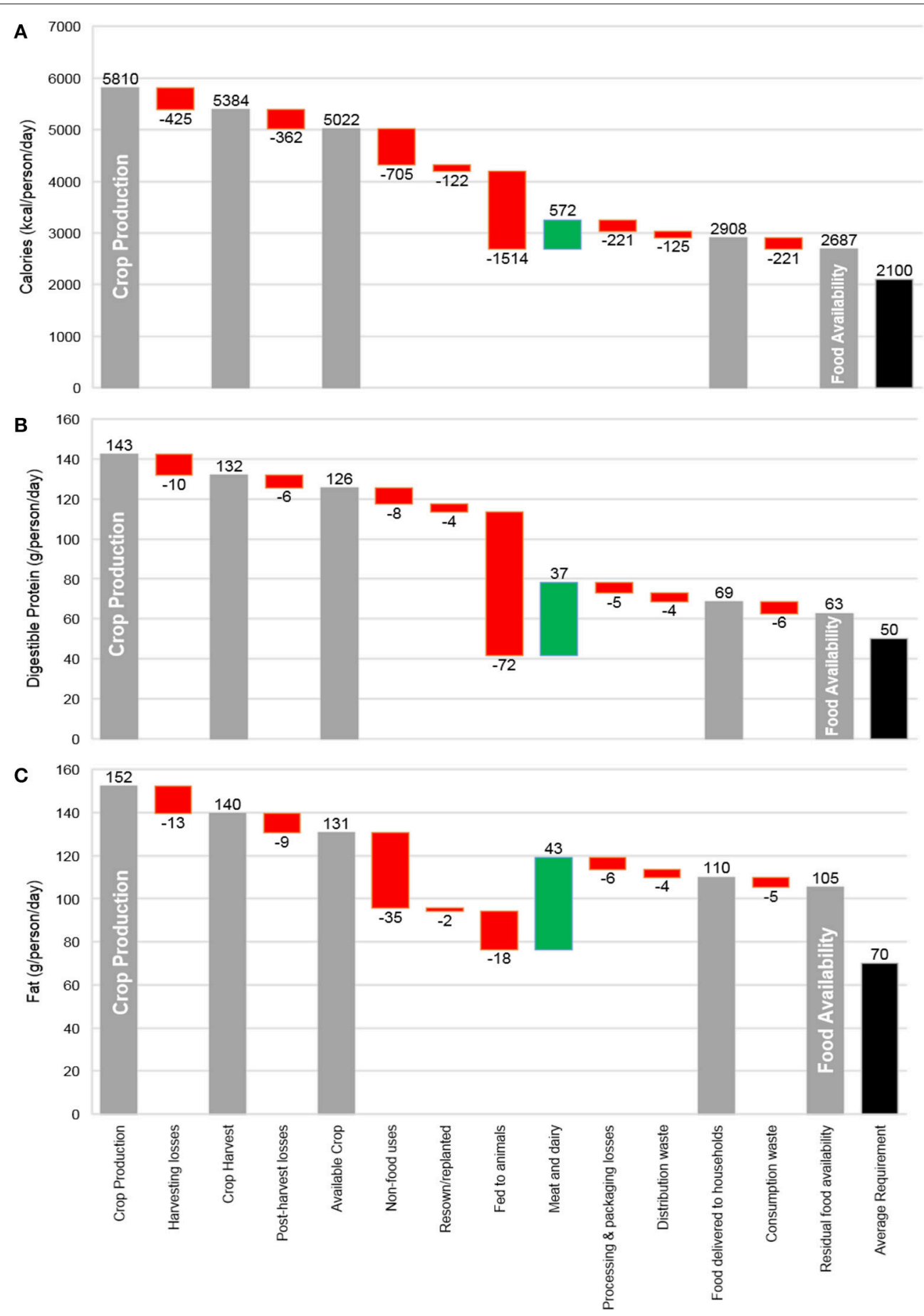

FIGURE 1 | Production and losses in the global food system from "field to fork" in 2011. Food pathways in (A) calories; (B) digestible protein; and (C) fat from crop production to residual food availability, normalized to average per capita levels assuming equal distribution. Red bars (negative numbers) indicate food system losses; green bars indicate meat and dairy production; and gray bars indicate macronutrient availability at intermediate stages of the chain with the minimum average requirement shown in black.

production and use chain in order to identify key inefficiencies and potential intervention points.

The pathways of energy, digestible protein and fat from "fieldto-fork" have both similarities and conflicting patterns, which are important to consider when defining potential entry points for change. All chains experience severe losses across the value chain, with losses of 54, 56, and 31\% in energy, digestible protein and fat, respectively. The three nutritional components show 
similar patterns of loss in stages we would define as supply chain losses (harvesting, post-harvest, processing, distribution, and consumption) with moderate losses at all stages, and the highest in the harvesting phase. As has been previously documented, such patterns will be regionally variable and income-dependent, with major losses at the post-harvest stage in developing nations, and more wastage at the consumer level in higher-income households (Lipinski et al., 2013).

The dominant losses occur in the allocation of edible crops toward non-food uses and animal feed. This is where the pathways between nutrients differ. The diversion of both energy and fat to non-food uses are much larger than that of digestible protein. The largest commodities utilized for non-food purposes are in the form of oils and cereals. This is an expected result due to large allocation of these commodities for the production of biofuels and industrial products such as cosmetics, construction and polymer materials (Foley et al., 2011; Lu et al., 2011). The re-allocation of oils and cereals explains the comparably larger losses of energy and fat vs. digestible protein (which is in low concentration in cereals, and absent in liquid oil component of oilcrops; FAO, 2001).

The largest loss of energy and digestible protein occurs in the re-allocation of crops for animal feed. This is in contrast to fat, which generates a net surplus in the production of animal-based fats. Our analysis suggests that approximately $1,500 \mathrm{kcal}$ and $70 \mathrm{~g}$ of digestible protein pppd is diverted for feed. Whilst some energy and protein is converted and reenters the system in the form of meat and dairy products, both experience a significant net loss in this conversion process (Figures 1A,B). Cereals, roots, and high-quality protein crops such as soybeans form the largest sources of animal feed, which explains the basis of this loss. It is important to note that the complete nutrient flow in this process is not captured through mapping edible food energy content alone; there are also significant energy and protein inputs in the form of grazing, pasture and fodder (land use for animal production is estimated to account for approximately $75 \%$ of total agricultural land; Foley et al., 2011).

\section{Amino Acids}

Our analysis has mapped the aggregate amino acid concentrations of all indispensable AAs by stage in the supply chain (Table 1). The amino acid profile is of lower importance where digestible protein availability is above requirements (as shown in Figure 1). However, in particular national or local settings where protein intake is below requirements, such analysis could help to identify where particular AAs are deficient, and where in the food chain they are produced or lost.

At the level of global food consumption, no AAs are deemed to be limiting in the average global diet. However, we have highlighted lysine as the amino acid of particular concern. As is clearly demonstrable in our analysis, and has been widely discussed within the literature (WHO/FAO/UNU Expert Consultation, 2007; Swaminathan et al., 2012), there is a significant contrast in the lysine concentration of plant- and animal-based products. The lysine concentration of aggregate commodities in the crop production and harvest phases of the supply chain is notably lower than the latter stages, where animal-based products are introduced. Whilst the average diet is not lysine-deficient, if meat and dairy products were removed, the global food system would be severely lysine-limited. At the crop production level, the average lysine concentration is $36.6 \mathrm{mg} \mathrm{g}_{\text {protein }}{ }^{-1}$, much lower than the required value of $46.1 \mathrm{mg} g$ protein $^{-1}$. The only component of the crop-based system for which the overall lysine concentration is above this requirement-and only marginally, at $46.9 \mathrm{mg} \mathrm{g}$ protein $^{-1}$-is the portion allocated for animal feed.

TABLE 1 | Aggregate amino acid profiles by stage in food supply chain.

\begin{tabular}{|c|c|c|c|c|c|c|c|c|c|}
\hline & Isoleucine & Leucine & Lysine & $\begin{array}{l}\text { Methionine } \\
\text { + Cysteine }\end{array}$ & $\begin{array}{c}\text { Phenylalanine } \\
\text { + Tyrosine }\end{array}$ & Threonine & Tryptophan & Valine & Histidine \\
\hline Crop production & 35.0 & 54.9 & 36.6 & 26.4 & 61.4 & 28.0 & 9.6 & 39.1 & 19.8 \\
\hline Harvesting losses & 40.9 & 66.0 & 44.4 & 25.9 & 62.3 & 40.6 & 21.3 & 0.0 & 0.0 \\
\hline Crop harvest & 34.6 & 54.1 & 36.0 & 26.5 & 61.3 & 27.0 & 8.7 & 42.1 & 21.4 \\
\hline Post-harvest losses & 34.5 & 52.9 & 32.6 & 26.0 & 58.7 & 24.1 & 7.9 & 38.5 & 19.4 \\
\hline Available crop & 34.6 & 54.1 & 36.2 & 26.5 & 61.5 & 27.2 & 8.7 & 42.3 & 21.5 \\
\hline Non-food uses & 17.9 & 36.4 & 17.8 & 15.1 & 37.9 & 16.7 & 4.5 & 24.4 & 11.8 \\
\hline Resown/replanted & 35.7 & 48.5 & 39.1 & 30.7 & 70.4 & 30.2 & 11.2 & 43.0 & 21.2 \\
\hline Fed to animals & 37.4 & 64.8 & 46.9 & 27.2 & 63.8 & 32.3 & 10.8 & 43.4 & 22.7 \\
\hline Meat and dairy & 55.4 & 96.1 & 103.0 & 40.5 & 89.9 & 49.5 & 13.8 & 61.3 & 36.3 \\
\hline Production and packaging losses & 51.8 & 76.6 & 56.0 & 29.0 & 69.5 & 34.3 & 10.8 & 42.6 & 24.8 \\
\hline Distribution waste & 53.4 & 85.5 & 75.2 & 31.8 & 77.8 & 40.8 & 12.0 & 50.5 & 28.9 \\
\hline Food delivered to households & 41.5 & 63.0 & 56.6 & 33.4 & 74.0 & 32.9 & 9.2 & 52.4 & 28.1 \\
\hline Consumption waste & 43.8 & 61.3 & 55.0 & 32.9 & 72.2 & 34.0 & 11.1 & 44.7 & 25.4 \\
\hline Residual food availability & 41.3 & 63.1 & 56.8 & 33.4 & 74.2 & 32.7 & 9.0 & 53.1 & 28.4 \\
\hline Population-weighted requirement & 30.1 & 59.5 & 46.1 & 22.5 & 39.1 & 23.6 & 6.2 & 39.4 & 15.4 \\
\hline
\end{tabular}

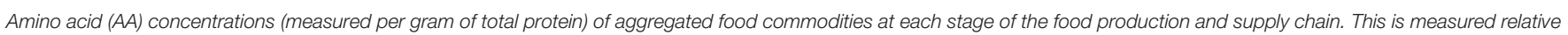
to derived population-weighted requirement values.

Values in bold represent average final food availability for consumers, with reference to average requirements shown in italics. 
This finding is important for several reasons. Diets low in intakes of animal-based products-especially those limited for economic reasons (where higher-quality alternatives such as pulses and legumes are not widely consumed) are likely to be lysine-limited. After correction for protein digestibility, this limitation further reduces the level of utilizable protein consumed in low-income settings (WHO/FAO/UNU Expert Consultation, 2007).

It also has important implications for the promotion of more sustainable plant-based diets. It's widely acknowledged that the resource footprints of animal-based products are typically higher than crop-based alternatives (Tilman and Clark, 2014), driving efforts for the adoption of more plantbased or vegetarian dietary habits (Ranganathan et al., 2016). However, our analysis suggests that our current food system would be severely lysine-limited in the absence of meat and dairy products. Although feed conversion in the production of livestock is inefficient-with large losses of energy and digestible protein-it is essential within our current food system to meet lysine requirements. This does not imply that a global shift toward a plant-based diet could not meet these requirements, however, a major shift in overall agricultural production toward more protein-based crops such as pulses and legumes would be necessary. Since the energy content of these commodities is typically lower than that of staple carbohydrate crops (FAO, 2001; USDA, 2016), the displacement of agricultural land used for cereal production may result in an overall reduction in total global caloric output. This is an important balance to assess in meeting the caloric, protein and lysine requirements of a growing population. This makes the extension of future analyses beyond caloric production even more essential.

\section{Micronutrients}

The pathways of individual micronutrients are presented in Figures 2A-C, 3A-C, 4A,B. As shown, all micronutrients meet their EAR in the global average availability. However, there are several micronutrients for which this is marginal. For example, the average availability of calcium is $953 \mathrm{mg}$ pppd relative to $877 \mathrm{mg}$ pppd requirements. Similarly, the availability of folate is only marginally higher than its EAR (with an intake of $313 \mu \mathrm{g}$ ppd vs. $299 \mu \mathrm{g}$ ppd requirements). This would be sufficient if diets were perfectly equitable, however, large geographical variations in dietary availability-especially in micronutrients which, like digestible protein, are typically more income dependent than caloric supply (Drewnowski, 2010)mean that many will consume well below EARs.

Micronutrient pathways demonstrate a trade-off similar to calorie, protein and lysine balances in relation to livestock production. As shown (Figures 2-4), the largest supply chain losses of several micronutrients (folate, zinc, iron, vitamin A and calcium) occur in the allocation of crops to animal feed. Whilst this highlights an important inefficiency in the food system, it's essential in the production of vitamin $\mathrm{B}_{12}$, for which animalbased products are the only dietary source (Wu et al., 2014). This dependence on meat and dairy products is likely to leave many individuals at risk of deficiency (especially in calcium, iron, zinc, folate vitamin A, C, and B-vitamins), especially those in lower income groups.

Our results indicate that the magnitude of total micronutrient loss from "field-to-fork" is typically higher than that of macronutrients. All micronutrients assessed in this study-with the exception of vitamin $B_{12}$-experience total losses of over $60 \%$. In the case of folate, this inefficiency reaches $71 \%$. This result is a reflection of the large losses and wastage of highly perishable foods, such as fruits, vegetables and animal-based products (FAO, 2011b).

\section{Data Limitations}

The challenge in developing accurate Food Balance Sheets (FBS) at the national and global level are widely acknowledged and discussed by the FAO (FAO, 2001). The accuracy of FBS is constrained by the completeness and reliability of commodity production and utilization statistics in national records.

Food loss and waste figures, especially in countries where small-holder farms and local markets are prevalent, has a high level of uncertainty. To our knowledge, statistics on supply chain losses and waste down to the national level are not widely available, particularly at the resolution of commodity and chain stage breakdown. For this reason, published commodityspecific FAO figures on regional losses have been applied in this study (Supplementary Table 2). A reliance on aggregated regional values reduces the resolution to which supply chain losses can be quantified, and introduces an additional degree of uncertainty.

Where data within FBS are deemed to be incomplete or inconsistent, the FAO draw upon judgements from national expert opinion and technical expertise to provide as reflective coverage as possible in its FBS. Whilst likely to provide a close approximation, this is rarely $100 \%$ accurate.

Nonetheless, the FBS is currently the best available data source for construction and analysis of the complete commodity chain. Literature is available based on studies conducted at the household level (Swaminathan et al., 2012), however, very few studies attempt to provide coverage of the food chain dynamics from crop production through to human consumption, especially on a global basis as in the present study. Without a complete overview of the commodity chain, the impacts of interventions (such as improved food management and storage; trade; reduced allocation of crops to non-food uses; improved crop yields) are almost impossible to assess.

As the FAO notes, food balance sheets "provide an approximate picture of the overall food situation in a country and can be useful for economic and nutritional studies, for preparing development plans and for formulating related projects" (FAO, 2001). In this study, we have therefore relied on FAO datasets in order to construct a high-level overview of the global commodity chain to assess its overall capacity to meet nutritional demands at present. This overview will not be perfect in a statistical sense, however these issues are global in scale and hence we deem the analysis to be appropriate to inform broad policy focus and assess the potential of supply chain interventions.

Improved agricultural, food waste and nutritional reporting would allow for more robust estimates to be constructed. Such 

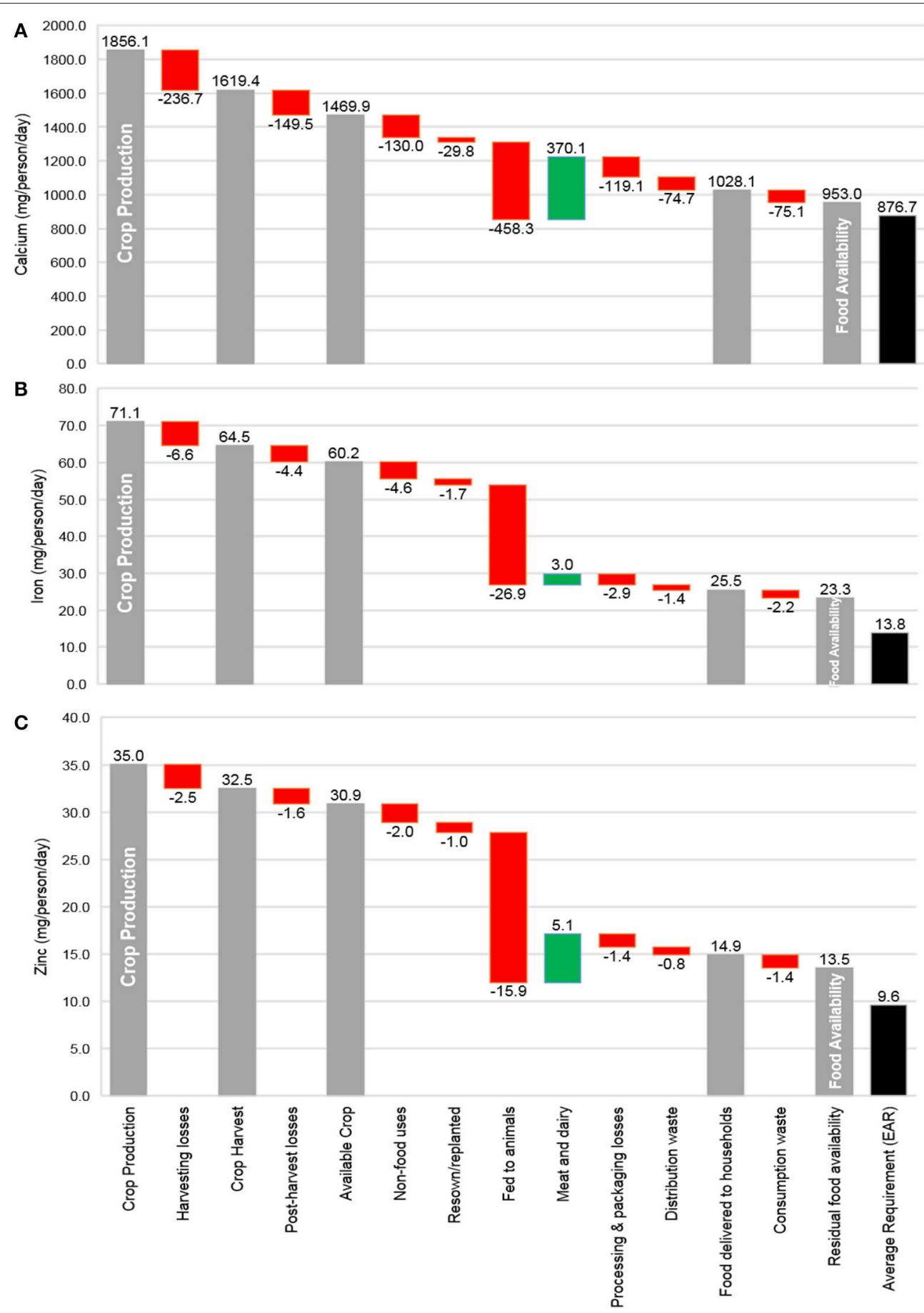

FIGURE 2 | Production and losses of micronutrients in the global food system from "field to fork" in 2011. Food pathways in (A) calcium; (B) iron; and (C) zinc from crop production to residual food availability, normalized to average per capita levels assuming equal distribution. Red bars (negative numbers) indicate food system losses; green bars indicate meat and dairy production; gray bars indicate macronutrient availability at intermediate stages of the chain, with the estimated average requirement shown in black.

data collection will be important in informing future policy and allowing for forward planning in this sector. It should therefore be an area of renewed focus for global food and nutritional assessment in the coming years.

\section{CONCLUSION}

This study has attempted to holistically map the global food commodity and nutrient system from agricultural production 

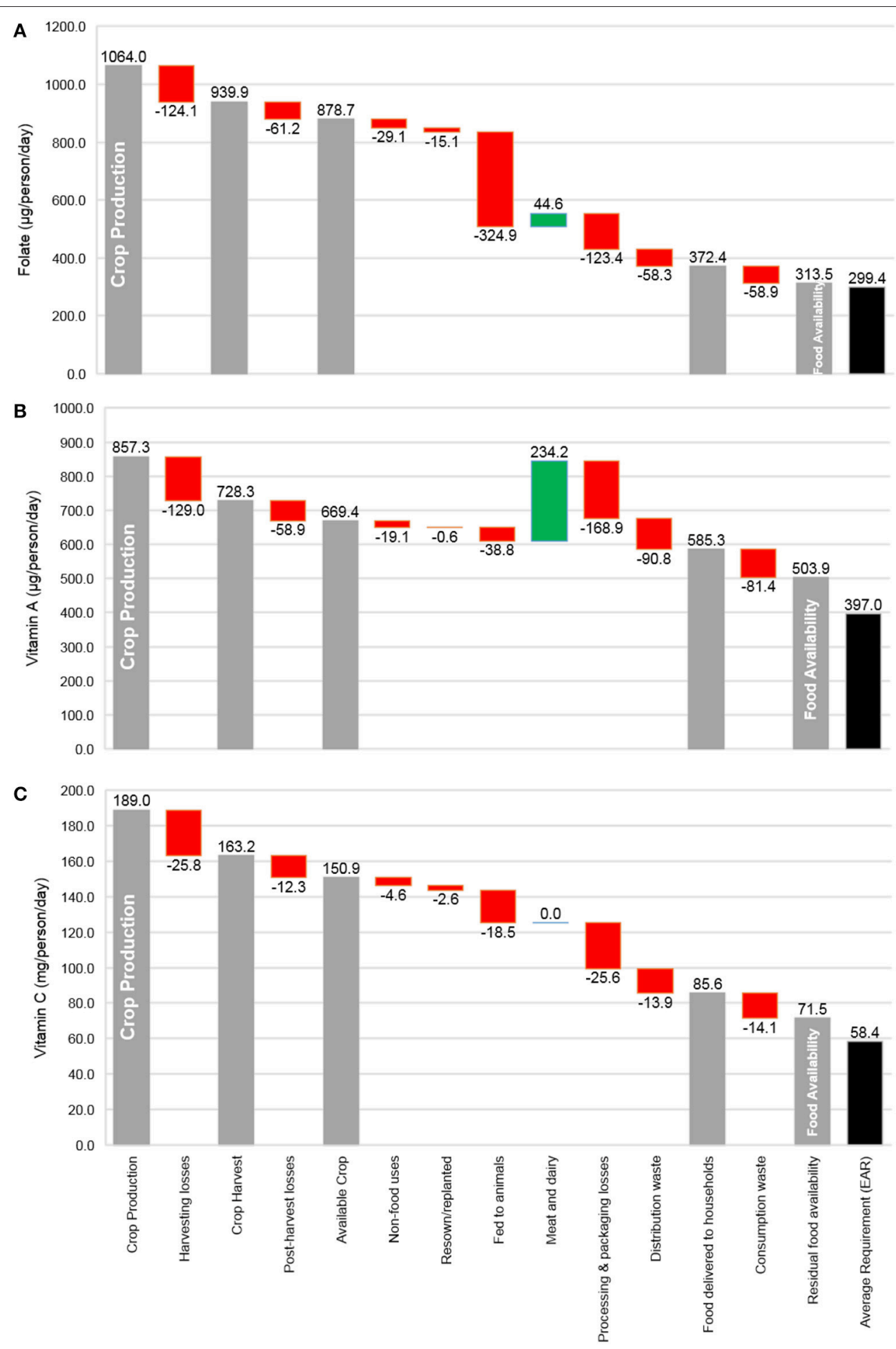

FIGURE 3 | Production and losses of micronutrients in the global food system from "field to fork" in 2011. Food pathways in (A) folate; (B) vitamin A; and (C) vitamin C from crop production to residual food availability, normalized to average per capita levels assuming equal distribution. Red bars (negative numbers) indicate food system losses; green bars indicate meat and dairy production; and gray bars indicate macronutrient availability at intermediate stages of the chain, with the estimated average requirement shown in black. 

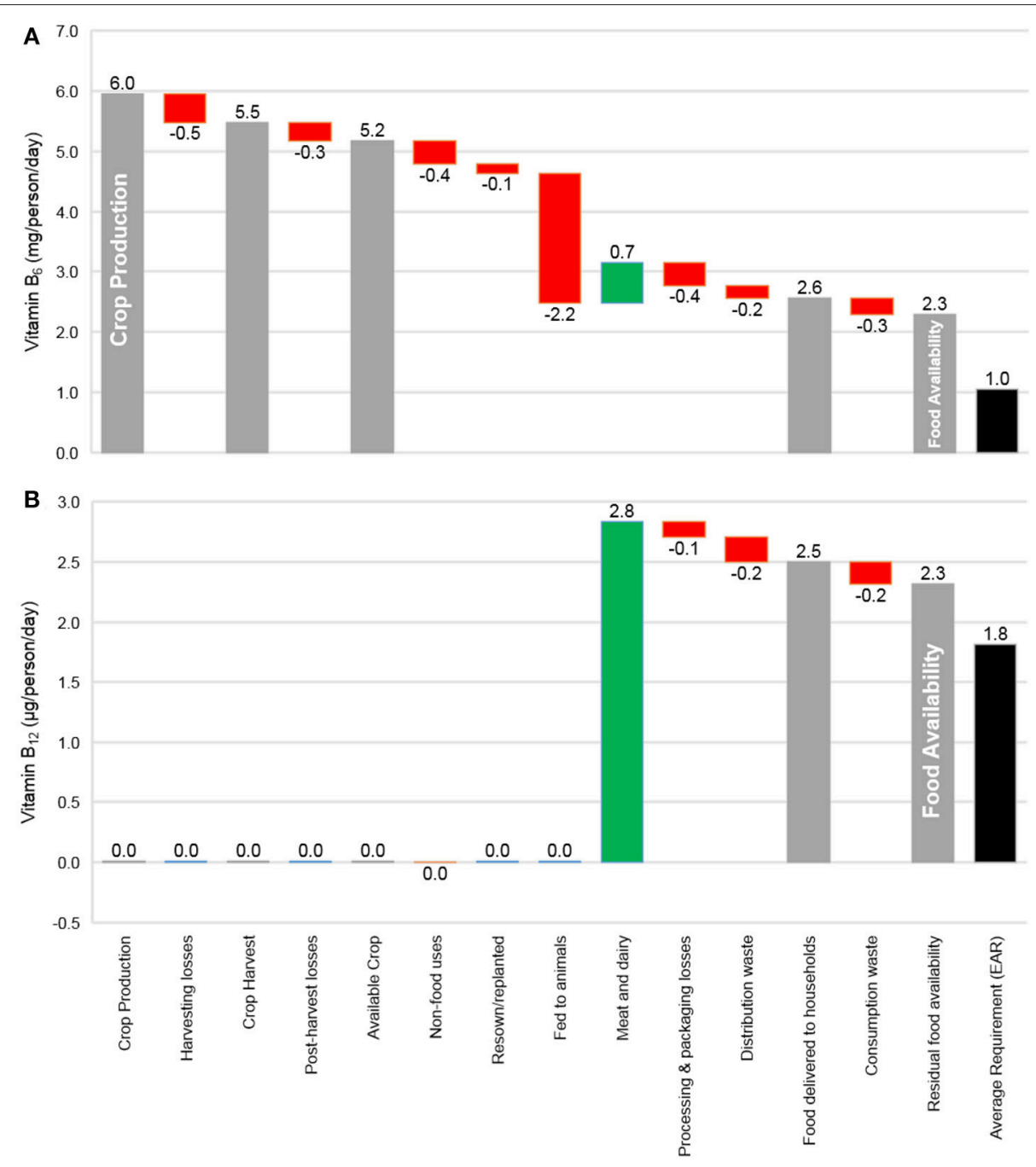

FIGURE 4 | Production and losses of micronutrients in the global food system from "field to fork" in 2011. Food pathways in (A) vitamin $B_{6}$; and (B) vitamin $B_{12}$ from crop production to residual food availability, normalized to average per capita levels assuming equal distribution. Red bars (negative numbers) indicate food system losses; green bars indicate meat and dairy production; and gray bars indicate macronutrient availability at intermediate stages of the chain, with the estimated average requirement shown in black.

through to food eaten-a system which is complex, and in some cases, poorly quantified. To maintain methodological consistency, we have utilized FAO FBS, regional waste and nutrient composition data as far as possible-the FAO is currently the only data repository from which such a global analysis can be sourced. The uncertainty around FBS and waste data is fully acknowledged by the FAO (FAO, 2001). As such, we acknowledge that our analysis is not perfect in a statistical sense (see section Data Limitations), however, it is currently the best estimate of the global food nutrient system to date.

Our analysis further highlights the importance of extending food and nutrient analysis beyond the scope of caloric supplycomplex trade-offs arise in sufficient production of energy, specific macronutrients, amino acids and micronutrients. Meeting future food demand (and SDG2 targets) requires a holistic overview of each across the full commodity system. It is from this starting point that the focus and efficacy of interventions can be quantified and balanced to better meet global nutritional demands. The effectiveness of particular interventions is likely to be componentdependent. For example, the disproportionately large losses of many micronutrients across the supply chain mean that strategies which focus on improved storage and distribution management are likely to improve micronutrient availability even more than macronutrient availability. Balancing and optimizing these intervention options to meet context-specific deficiencies is vital in reducing the scale of global nutrient deficiency.

Despite providing an important global overview of the overall food system, this analysis has limitations in its effectiveness at capturing regional, national and local system dynamics. 
That said, this framework is highly replicable-FAO data exist at regional and national levels - and can be scaled for more context-specific nutritional analysis. Such scalability will allow for better coverage of the dietary inequalities which exists both between and within countries.

\section{AUTHOR CONTRIBUTIONS}

HR conceptualized the research, developed the methodology and carried out the analysis. All authors contributed to writing the paper.

\section{REFERENCES}

Ahmed, T., Hossain, M., and Sanin, K. I. (2012). Global burden of maternal and child undernutrition and micronutrient deficiencies. Ann. Nutr. Metabol. 61, 8-17. doi: 10.1159/000345165

Alexandratos, N., and Bruinsma, J. (2012). World agriculture: towards 2030/2050: an FAO perspective. Land Use Policy 20, 375. doi: 10.1016/S0264-8377(03)00047-4

BajŽelj, B., Richards, K. S., Allwood, J. M., Smith, P., Dennis, J. S., Curmi, E., et al. (2014). Importance of food-demand management for climate mitigation. Nat. Climate Change 4, 924-929. doi: 10.1038/nclimate2353

Bouis, H. E., Eozenou, P., and Rahman, A. (2011). Food prices, household income, and resource allocation: socioeconomic perspectives on their effects on dietary quality and nutritional status. Food Nutr. Bull. 32, 14-23. doi: $10.1177 / 15648265110321$ S103

Bray, G. A., Paeratakul, S., and Popkin, B. M. (2004). Dietary fat and obesity: a review of animal, clinical and epidemiological studies. Physiol. Behav. 83, 549-555. doi: 10.1016/j.physbeh.2004. 08.039

Brown, M. J., Ferruzzi, M. G., Nguyen, M. L., Cooper, D. A., Eldridge, A. L., Schwartz, S. J., et al. (2004). Carotenoid bioavailability is higher from salads ingested with full-fat than with fat-reduced salad dressings as measured with. Am. J. Clin. Nutr. 80, 396-403. doi: 10.1093/ajcn/80. 2.396

Cassidy, E. S., West, P. C., Gerber, J. S., and Foley, J. A. (2013). Redefining agricultural yields: from tonnes to people nourished per hectare. Environ. Res. Lett. 8, 1-8. doi: 10.1088/1748-9326/8/3/034015

Davis, K. F., and D'Odorico, P. (2015). Livestock intensification and the influence of dietary change: a calorie-based assessment of competition for crop production. Sci. Total Environ. 538, 817-823. doi: 10.1016/j.scitotenv.2015.08.126

Drewnowski, A. (2010). The cost of US foods as related to their nutritive value. Am. J. Clin. Nutr. 92, 1181-1188. doi: 10.3945/ajcn.2010. 29300

Dror, D. K., and Allen, L. H. (2011). The importance of milk and other animalsource foods for children in low-income countries. Food Nutr. Bull. 32, 227-243. doi: 10.1177/156482651103200307

FAO (2001). Food Balance Sheets Handbook. FAOstats. Rome. Available online at: http://www.fao.org/faostat/en/

FAO (2011a). Dietary Protein Quality Evaluation in Human Nutrition. Food and Agriculrure Organization of the United Nations. Available online at: http://http://www.fao.org/ag/humannutrition/3597802317b979a686a57aa4593304ffc17f06.pdf

FAO (2011b). Global Food Losses and Food Waste - Extent, Causes and Prevention. Rome: UN Food and Agriculture Organization.

FAO (2016). FAO/INFOODS Food Composition Databases. Available online at: http://www.fao.org/infoods/infoods/tables-and-databases/faoinfoodsdatabases/en/ (Accessed November 28, 2016).

FAO (2017a). Food-Based Dietary Guidelines. Rome.

FAO (2017b). The Future of Food and Agriculture - Trends and Challenges. Rome: UN Food and Agriculture Organization.

\section{FUNDING}

This research was funded by the UK Natural Environment Research Council (NERC, grant number: NE/L002558/1) under its E3 Doctoral Training Programme (DTP).

\section{SUPPLEMENTARY MATERIAL}

The Supplementary Material for this article can be found online at: https://www.frontiersin.org/articles/10.3389/fsufs. 2018.00057/full\#supplementary-material

FAO, IFAD, and WFP. (2015). The State of Food Insecurity in the World: Meeting the 2015 International Hunger Targets: Taking Stock of Uneven Progress. Rome: FAO, IFAD and WFP.

FAO. (n.d.). FAOstat Database. Available online at: http://www.fao.org/faostat/ en/\#data/FBS (Accessed January 6, 2017).

FAO/WHO (2008). Fats and Fatty Acids in Human Nutrition, Report of an expert consultation. Report of an Expert Consultation (Vol. 91). Rome: UN FAO and World Health Organization.

Foley, J. A., Ramankutty, N., Brauman, K. A., Cassidy, E. S., Gerber, J. S., Johnston, M., et al. (2011). Solutions for a cultivated planet. Nature 478, 337-342. doi: $10.1038 /$ nature 10452

Haddad, L., Hawkes, C., Webb, P., Thomas, S., Beddington, J., Waage, J., et al. (2016). A new global research agenda for food. Nature 540, 30-32. doi: $10.1038 / 540030$ a

Horton, S., and Steckel, R. (2011). Malnutrition: Global Economic Losses Attributable to Malnutrition 1900-2000 and Projections to 2050. Copenhagen: Copenhagen Consensus on Human Challenges.

International Food Policy Research Institute (2016). Global Nutrition Report-From Promise to Impact: Ending Malnutrition by 2030. Washington D.C: IFPRI.

IPCC (2014). "AR5 WGIII chapter 11-agriculture, forestry and other land use (AFOLU)," in Climate Change 2014: Mitigation of Climate Change. Contribution of Working Group III to the Fifth Assessment Report of the Intergovernmental Panel on Climate Change, eds O. Edenhofer, R. Pichs-Madruga, Y. Sokona, E. Farahani, S. Kadner, K. Seyboth, et al. (Geneva).

Lipinski, B., Hanson, C., Waite, R., Searchinger, T., Lomax, J., and Kitinoja, L., et al. (2013). "Reducing food loss and waste," in Working Paper, Installment 2 of Creating a Sustainable Food Future. Washington, DC: World Resources Institute. Available online at: http://www.worldresourcesreport.org

Lu, C., Napier, J. A., Clemente, T. E., and Cahoon, E. B. (2011). New frontiers in oilseed biotechnology: meeting the global demand for vegetable oils for food, feed, biofuel, and industrial applications. Curr. Opin. Biotechnol. 22, 252-259. doi: 10.1016/j.copbio.2010.11.006

Malik, V. S., Willett, W. C., and Hu, F. B. (2013). Global obesity: trends, risk factors and policy implications. Nat. Rev. Endocrinol. 9, 13-27. doi: $10.1038 /$ nrendo.2012.199

Miller, D. D., and Welch, R. M., (2013). Food Systems Strategies for Preventing Micronutrient Malnutrition. (Rome: UN Food and Agriculture Organization), 115-128. doi: 10.1016/j.foodpol.2013.06.008

Ranganathan, J., Vennard, D., Waite, R., Dumas, P., Lipinski, B., and Searchinger, T. (2016). Washington, DC: Shifting Diets for a Sustainable Food Future.

Ritchie, H., Reay, D., and Higgins, P. (2018). Sustainable food security in Indiadomestic production and macronutrient availability. PLOS ONE 13:e0193766. doi: 10.1371/journal.pone.0193766

Sukhdev, P., May, P., and Müller, A. (2016). Fix food metrics. Nature 540, 33-34. doi: $10.1038 / 540033$ a

Swaminathan, S., Vaz, M., and Kurpad, A. V. (2012). Protein intakes in India. Br. J. Nutr. 108, S50-S58. doi: 10.1017/S0007114512002413

Tilman, D., and Clark, M. (2014). Global diets link environmental sustainability and human health. Nature 515, 518-522. doi: 10.1038/nature13959

UNHCR/UNICEF/WFP/WHO (2004). Food and Nutrition Needs in Emergencies. Geneva: United Nations. 
United Nations (2001). Road Map Towards the Implementation of the United Nations Millennium Declaration. New York, NY: United Nations.

United Nations (2015a). Transforming our World: The 2030 Agenda for Sustainable Development 16301. New York, NY: Vol. 16301.

United Nations (2015b). UN Population Prospects. Available online at: http://esa. un.org/unpd/wpp/ (Accessed February 6, 2016).

United Nations: Department of Social and Economic Affairs (2013). World Population Prospects: The 2012 Revision, DVD edition. Population Division 2013. Available online at: http://esa.un.org/unpd/wpp/Excel-Data/population. htm.

USDA (2016). USDA Food Composition Databases. Avaialble online at: https://ndb. nal.usda.gov/ndb/ (Accessed November 28, 2016).

Varadharajan, K. S., Thomas, T., and Kurpad, A. V. (2013). Poverty and the state of nutrition in India. Asia Pac. J. Clin. Nutr. 22, 326-339. doi: 10.6133/apjen.2013.22.3.19

von Grebmer, K., Saltzman, A., Birol, E., Wiesmann, D., Prasai, N., Yin, S., et al. (2014). 2014 Global Hunger Index: The Challenge of Hidden Hunger, Vol. 12. Bonn; Washington, DC; Dublin: IFPRI.

White, W. S., Zhou, Y., Crane, A., Dixon, P., Quadt, F., and Flendrig, L. M. (2017). Modeling the dose effects of soybean oil in salad dressing on carotenoid and fat-soluble vitamin bioavailability in salad vegetables. Am. J. Clin. Nutr. 106, 1041-1051. doi: 10.3945/ajcn.117.153635

WHO/FAO/UNU Expert Consultation (2007). Protein and Amino Acid Requirements in Human Nutrition. Geneva: World Health Organization Technical Report Series.
World Health Organization (1991). Energy and Protein Requirements. Geneva. Available online at: http://www.fao.org/docrep/003/aa040e/AA040E00.htm\# TOC.

World Health Organization (2005). Vitamin and Mineral Requirements in Human Nutrition: Report of a Joint FAO/WHO Expert Consultation. Geneva: World Health Organization.

Wu, G. (2016). Dietary protein intake and human health. Food Funct. 7, 1251-1265. doi: 10.1039/c5fo01530h

Wu, G., Fanzo, J., Miller, D. D., Pingali, P., Post, M., Steiner, J. L., et al. (2014). Production and supply of high-quality food protein for human consumption: Sustainability, challenges, and innovations. Ann. N. Y. Acad. Sci. 1321, 1-19. doi: 10.1111/nyas. 12500

Conflict of Interest Statement: The authors declare that the research was conducted in the absence of any commercial or financial relationships that could be construed as a potential conflict of interest.

Copyright (C) 2018 Ritchie, Reay and Higgins. This is an open-access article distributed under the terms of the Creative Commons Attribution License (CC BY). The use, distribution or reproduction in other forums is permitted, provided the original author(s) and the copyright owner(s) are credited and that the original publication in this journal is cited, in accordance with accepted academic practice. No use, distribution or reproduction is permitted which does not comply with these terms. 